\title{
O ESTADO DE EXCEÇ̃̃O COMO ELEMENTO ESSENCIAL DO CONCEITO DE ESTADO-NAÇÃO, O CAMPO E OS NEOMORTOS CONTEMPORÂNEOS
}

\author{
[THE STATE OF EXCEPTION AS AN ESSENTIAL ELEMENT OF THE CONCEPT OF NATION-STATE, \\ THE FIELD AND CONTEMPORARY NEO-DEADS]
}

\author{
Vinicius de negreiros Calado * \\ João Paulo Fernandes de Souza Allain Teixeira ** \\ Universidade Católica de Pernambuco, Brasil
}

Resumo: O presente artigo tem como marco teórico os estudos de Giorgio Agamben, partindo de sua análise do conceito clássico de Estado-nação, afigurando-se o campo como um novo elemento essencial desse, compreendendo-se o estado de exceção não como a clássica suspensão normativa temporária, mas sim como uma localização deslocante contida no espaço territorial, a qual deve ser entendida como técnica de governo. Essa técnica estaria presente contemporaneamente, mesmo nos estados chamados democráticos ainda que o estado de exceção não seja abertamente declarado. Analisa-se o direito sobre a vida e a morte daqueles que se encontram inseridos nesse espaço deslocalizado como questão central da biopolítica, na medida em que a ciência médica redefine o conceito de morte, a chamada morte cerebral, constatando-se que a vida e a morte possuem fronteiras móveis. Observa-se que no Brasil, a legislação se utiliza exclusivamente de critérios do Conselho Federal de Medicina (CFM) para o estabelecimento da morte cerebral, a qual fora utilizada como fundamento da procedência da ADPF $\mathrm{n}^{\mathrm{o}} 54$. Com base em Michel Foucault refere-se às transformações sofridas pela instituição hospitalar, destacando o aumento do poder
ABSTRACT: This article has as its theoretical framework the studies of Giorgio Agamben, starting his analysis of the classic concept of the nation-state, configuring the field as a new essential element of this type, understanding the state of exception not as the classic suspension of the temporary regulation, but rather as a displaced location in territorial space, which should be understood as a government technique. This technique is present nowadays in democratic states even though the state of exception is not openly stated. The article analyzes the right to life and death of those who are inserted in this displaced space as a central issue of biopolitics, as medical science redefines the concept of death, brain death or death, finding that life and death has moving borders. The fusion between medicine and politics is found to be one of the essential features of modern biopolitics, where there is an exchange of roles in which the physician decides as much as the sovereign once decided. Finally, it is suggested that one cannot lose sight of the fact that the field and the state of exception are always virtually present and that scientific knowledge can at any

* * Professor Assistente II de Direito Civil, Direito do Consumidor e Orientação Monográfica na UNICAP (desde 2011). Doutor em Direito (2020) pela Universidade Católica de Pernambuco UNICAP. Pesquisador do Grupo de Pesquisa Linguagem e Direito (Unicap/CNPq). E-mail: vinicius.calado@unicap.br. ** Professor Adjunto na Universidade Federal de Pernambuco, Professor na Universidade Católica de Pernambuco e Professor nas Faculdades Integradas Barros Melo. Pesquisador do CNPq (bolsa produtividade em pesquisa nível 2). Doutor em Direito pela Universidade Federal de Pernambuco (2005).E-mail: jpallain@unicap.br 
médico, bem como a crítica de Agamben ao autor porque ele não teria avançado em seus estudos para o campo de concentração, posto que fora nestes que ocorrera o ápice da biopolítica (tanatopolítica). Verifica-se que a fusão entre a medicina e a política é uma das características essenciais da biopolítica moderna, onde há uma troca de papéis em que o médico decide tanto quanto outrora decidia o soberano. Sugere-se, por fim, que não se pode perder de vista que o campo e o estado de exceção estão sempre virtualmente presentes e que o conhecimento científico pode, a qualquer tempo, ser utilizado pelo poder estatal, com os riscos inerentes às conveniências do governo.

Palavras-chave: Estado de exceção; Biopolítica; Poder médico time be used by state power, with the risks inherent in the convenience of the government.

KeYwords: Exception state; Biopolitics; Medical power

\section{INTRODUÇÃo}

presente trabalho tem como base e fundamento teórico a obra do filósofo italiano Giorgio Agamben, o qual, segundo Castro, em obra introdutória ao seu pensamento, o filósofo "ocupa um lugar cada vez mais destacado no panorama do pensamento contemporâneo" justamente por enfrentar a "politização moderna da vida biológica" (2012, p. 9).

Agamben analisa a chamada vida nua e como o Estado se apropria do poder decisório sobre a mesma, revisitando o conceito de Estado-nação e propondo novos paradigmas.

Em sua teorização "o estado de exceção é o dispositivo por meio do qual o poder soberano captura a vida" (CASTRO, 2012, p. 75).

Assim, busca-se abordar os conceitos tradicionais de estado-nação, bem como a noção de campo (decorrente de campo de concentração) em Agamben, para num segundo momento descrever como o campo transformou-se em técnica de governo a partir da politização da vida nua, introduzindo-se o conceito de neomortos.

Com base em Michel Foucault explora-se a questão do poder da ciência médica e o patamar a que a mesma fora alçada, chamando-se atenção para os riscos que advém da biopolitização, usando-se como exemplo no Brasil o conceito jurídico de morte cerebral.

\section{Estrado-NaÇão e a noÇão de CAMPo em Agamben}

$\mathrm{O}$ conceito de Estado-nação moderno parece não mais ser suficiente para a contemporaneidade, encontrando-se em crise, tendo em vista que os elementos tidos por essenciais passam a não mais se mostrarem presentes em certas conjunturas.

Do ponto de vista clássico o entendimento predominante é o de que os três elementos essenciais do Estado moderno-contemporâneo são: território, população e “poder político institucionalizado e soberano." (CAVALCANTI, 1989, p. 98-99).

Já para Dallari aquilo que a maioria dos autores chama de elementos essenciais, ele prefere denominar de notas características. Refere o autor que não há consenso na doutrina, mas que muitos autores utilizam a terminologia elementos essenciais 
justamente por entenderem serem eles todos "indispensáveis para a existência do Estado", especificando que a "maioria dos autores indica três elementos, embora divirjam quanto a eles" (2007, p. 71).

Ainda segundo Dallari (2007, p.71):

De maneira geral, costuma-se mencionar a existência de dois elementos materiais, o território e o povo, havendo grande variedade de opiniões sobre o terceiro elemento, que muitos denominam formal. O mais comum é a identificação desse último elemento com o poder ou alguma de suas expressões, como autoridade, governo ou soberania.

Ao tratar dos elementos tidos por indispensáveis do Estado Moderno Lênio Streck e Bolzan de Morais (2004, p. 151) afirmam que esta concepção está em crise em virtude das "circunstâncias técnico-econômico-políticas que afetam profundamente tais elementos, tornando-os imprestáveis em sua concepção tradicional” para o reconhecimento do Estado contemporâneo.

Segundo Agamben o Estado-nação moderno se fundava "no nexo funcional entre determinada localização (o território) e um determinado ordenamento (o Estado)", mediado por regras automáticas de inscrição da vida (o nascimento ou nação)" (2015, p. 46), contudo

O deslocamento crescente entre o nascimento (a vida nua) e o Estado-nação é o fato novo da política do nosso tempo e o que chamamos de campo é esse resto. A um ordenamento sem localização (o estado de exceção, no qual a lei é suspensa) corresponde agora a uma localização sem ordenamento (o campo como espeço permanente de exceção). (2015, p. 46)

Neste sentido, caracteriza-se o campo como "[...] o espaço que se abre quando o estado de exceção começa a se tornar a regra" (AGAMBEN, 2015, p. 42), sendo "[...] um pedaço de território que é colocado fora do ordenamento jurídico normal." (AGAMBEN, 2015, p. 43)

Ainda segundo Agamben, "o campo como localização deslocadora é a matriz oculta da política em que ainda vivemos, a qual devemos aprender a reconhecer através de todas as suas metamorfoses" (2015, p. 47).

Assim, configura-se o campo como um novo elemento essencial do conceito de Estado-nação, sendo dele "inseparável" e que fora acrescentado "quebrando a velha trindade Estado-nação(nascimento)-território.” (2015, p. 47). constata que

É justamente na linha de abordagem crítica dos conceitos tradicionais que se

[...] é imperiosa a análise dos institutos atrelados à visão moderna de mundo, trazse a título de exemplo, soberania, lei, território, estado... Não porque esses institutos denotam explicitamente a concepção de modernidade, mas, sim, como âmago capaz de iludir e dissimular as práticas espúrias da colonização. (ROMAGUERA; TEIXEIRA; BRAGATO, On-line).

Desta feita, revisitado o conceito de Estado-nação e nele incluído como elemento essencial o campo, passa-se a análise pormenorizada na noção de campo em Agamben.

Ao abordar a teoria de Schmitt e os conceitos abertos Agamben afirma que eles não remetem para uma norma, mas para uma situação, pois deslocam a clareza e a calculabilidade para fora da norma (1998, p. 164), citando como exemplo da dificuldade o julgamento de Eichmann, o qual apenas aplicou como lei a palavra do 
Führer, lembrando-se que:

[...] o nacionalismo ou o patriotismo é a ideologia que une as classes, que as torna solidárias na competição internacional. Das cinco ideologias, entretanto, é a única que não é universal; que é limitada a cada nação. A radicalização de qualquer dessas ideologias traz conseqüências terríveis, mas as mais violentas são as do nacionalismo. Guerras, genocídios têm sempre origem no nacionalismo. (BRESSER-PEREIRA, On-line).

Agamben refere que encontramo-nos virtualmente na presença de um campo sempre que é criada uma estrutura semelhante (1998, p. 166), seja numa zona aeroportuária, seja num hotel, num local onde a polícia "age provisoriamente como soberana" (1998, p. 167), ou até mesmo "em certas periferias das nossas cidades" (1998, p. 168).

[...] se a essência do campo consiste na materialização do estado de exceção e na consequente criação de um espaço para a vida nua como tal, teremos que admitir, então, que nos encontramos virtualmente em presença de um campo todas as vezes em que for criado estrutura semelhante, independentemente da entidade dos crimes que são cometidos ali e qualquer que seja a sua denominação e topografia específica. (AGAMBEN, 2015, p. 45)

Aquilo que "era essencialmente uma suspensão temporal da ordem jurídica" em determinado espaço territorial (estado de exceção), é agora uma localização deslocante contida no espaço territorial (1998, p. 168), posto que

Uma das características essenciais do estado de exceção - a abolição provisória da distinção entre poder legislativo, executivo e judiciário - mostra, aqui, sua tendência a transformar-se em prática duradoura de governo. (AGAMBEN, 2004, p. 19)

Para Agamben, especificamente falando sobre os campos de concentração e extermínio nazistas, "o campo é somente o lugar no qual se realizou a absoluta condicio inhumana que se deu sobre a terra: isso é, em última análise, aquilo que conta, para as vítimas e para seus pósteros." (AGAMBEN, 2015, p. 41).

Assim considerando o campo como elemento essencial do Estado-nação contemporâneo, este passa a ser entendido como técnica de governo.

[....] os Estados contemporâneos agem em permanente estado de exceção, pois toma como fato político por excelência a vida do cidadão em sua centralidade biológica, fazendo viver, ou deixando morrer. O sujeito da soberania, no caso da exceção, não está limitado a um conjunto de competências, mas a uma decisão, que tem em si a presunção de um poder ilimitado, em circunstancia de um caso concreto. (SCZIMINSKI; BAZZANELA, 2013)

\section{O CAMPO COMO TÉCNICA DE GOVERNO}

Em obra introdutória ao pensamento de Agamben, Castro refere que "o espaço do campo aparecerá como o paradigma político da modernidade" (CASTRO, 2012, p. 68).

Na obra "Estado de Exceção" (2004), Agamben explora aquilo que ele chama de "terra de ninguém, entre o direito público e o fato político e entre a ordem jurídica e a vida", aduzindo que "somente erguendo o véu que cobre essa zona incerto poderemos chegar a compreender o que está em jogo na diferença - ou na suposta diferença entre o 
político e o jurídico e entre o direito e o vivente", pois o estado de exceção "apresentase como a forma legal daquilo que não pode ter legal", concluindo que "uma teoria do estado de exceção é, então, condição preliminar para de definir a relação que liga e, ao mesmo tempo, abandona o vivente ao direito" (p. 9).

Partindo da ideia de que o Terceiro Reich poderia ser considerado juridicamente "como um estado de exceção que durou 12 anos", aduz Agamben que

O totalitarismo moderno pode ser definido, nesse sentido, com a instauração, por meio do estado de exceção, de uma guerra civil legal que permite a eliminação física não só dos adversários políticos, mas também de categorias inteiras de cidadãos que, por qualquer razão, pareçam não integráveis ao sistema político. (2004, p. 12)

E chega a uma conclusão, que em certa medida chega a chocar o leitor desavisado, de que estas práticas estão presentes contemporaneamente nos estados chamados democráticos, ainda que não sejam declaradas em "sentido técnico", pois teria deixado de ser "uma medida provisória e excepcional" para se tornar "uma técnica de governo", a qual, por sua vez está transformando de modo radical "a estrutura e o sentido entre os diversos tipos de constituição", constituindo o estado de exceção "como um patamar de indeterminação entre democracia e absolutismo" (2004, p. 13).

Agamben compara os atos e leis americanas pós ataques de 11 de setembro de 2001 (military order e USA Patriot Act), com os campos de concentração, aduzindo que essas detenções são unicamente comparáveis "com a situação jurídica dos judeus nos Lager nazistas", tendo em vista que as mesmas autorizam detenções por prazo indefinido e permitem que estrangeiros sejam mantidos presos pelo prazo de 7 dias em determinados casos, inclusive referindo os casos dos talibãs "detidos" que não são "considerados prisioneiros nem acusados" e se encontram "totalmente fora da lei do controle do judiciário" (2004, p. 14).

Não é sem razão que a doutrina reconhece um crescimento de políticas autoritárias em todo o mundo:

Formou-se, na atualidade, considerável literatura crítica no sentido (da denúncia) da crescente e desordenada limitação dos direitos individuais, em um novo ciclo geoestratégico de tendências autoritárias. (FAYET JUNIOR; SOUZA, 2015, p. 54)

Outrossim, ao tratar da expressão "estado de exceção" Agamben afirma que "a terminologia é o momento propriamente poético do pensamento, então as escolhas terminológicas nunca podem ser neutras" e que esta escolha "implica numa tomada de posição quanto à natureza do fenômeno", pois o "estado de exceção não é um direito especial (como o direito de guerra), mas, enquanto suspensão da própria ordem jurídica, define seu patamar ou seu conceito limite." (2004, p. 15).

Uma das características essenciais do estado de exceção - a abolição provisória da distinção entre poder legislativo, executivo e judiciário - mostra, aqui, sua tendência a transformar-se em prática duradoura de governo. (2004, p. 19)

Partindo do adágio latino "a necessidade não tem lei (necessitas legem non habet)", o qual pode ser interpretado em dois sentidos opostos, quais sejam, "a necessidade não reconhece a lei" e a "necessidade cria a sua própria lei", Agamben aduz que "um estudo da estrutura e do significado do estado de exceção pressupõe, portanto, uma análise do conceito jurídico de necessidade" (2004, p.40), na medida em 
que

O estado de exceção, enquanto figura da necessidade, apresenta-se pois - ao lado da revolução e da instauração de fato de um ordenamento jurídico constitucional - como uma medida "ilegal", mas perfeitamente "jurídica a e constitucional", que se concretiza na criação de novas normas (ou de uma nova ordem jurídica). (2004, p.44)

Agamben tece críticas aos juristas que de modo "mais ou menos" inconscientes buscam pensar a natureza da necessidade "como uma situação objetiva", quando na verdade esta "[...] implica claramente um juízo subjetivo e que necessárias e excepcionais são, é evidente, apenas aquelas circunstâncias que são declaradas como tais." (2004, p. 46), concluindo que "não só a necessidade se reduz, em última instância, a uma decisão, como também aquilo sobre o que ela decide é, na verdade, algo indecidível de fato e de direito." (2004, p. 47).

Agamben afirma que a obra de Schimitt contém "a tentativa mais rigorosa de construir uma teoria do estado de exceção" (2004, p.53), e que sua teologia política "representa, indubitavelmente, a tentativa de ancorar sem restrições o estado de exceção na ordem jurídica" (p.57), posto que "o soberano, que pode decidir sobre o estado de exceção, garante sua ancoragem na ordem jurídica” (p.56).

Podemos definir então o estado de exceção na doutrina schimittiana como o lugar em que a oposição entre a norma e a sua realização atinge a máxima intensidade. Tem-se aí um campo de tensões jurídicas em que o mínimo de vigência formal coincide com o máximo de aplicação real e vice-versa. Mas também zona extrema, ou melhor, exatamente em virtude dela, os dois elementos do direito mostram sua íntima coesão. (AGAMBEN, 2004, p. 58)

Assim, fazendo o estado de exceção parte dos Estados-nação contemporâneos há quem advogue que, no Brasil, o uso abusivo das medidas provisórias dá conta dessa realidade:

A medida provisória que deveria ser medida excepcional, no entanto, tornou-se uma técnica de governo, do poder executivo que toma decisões num primeiro momento a revelia do poder legislativo, que se constitui como o poder representante por excelência dos interesses da sociedade. (SCZIMINSKI; BAZZANELA, 2013)

E ainda:

Diante dos amplos poderes legislativos por parte do Executivo Brasileiro, os quais se evidenciam pelo abuso das medidas provisórias, o mesmo utiliza de poderoso conjunto de instrumentos para controlar e muitas vezes determinar a agenda do Congresso Nacional, utilizando as normas disciplinadas na Carta Magna, legislando em situação que não lhe seja conveniente, desta forma construindo ao longo do tempo um estado de exceção. (SCZIMINSKI; BAZZANELA, 2013)

Nesse sentido, estar-se-ia diante de uma situação em que poderia "a política se servir do direito para pôr em prática seus objetivos" (STAMFORD DA SILVA, 2014, p.119), algo que tem grande probabilidade de ocorrer no caso de autoirritações sistêmicas (em sentido luhmanniano).

Contudo, uma das questões de maior relevo no tocante ao estado de exceção é a questão atinente à vida ou, melhor dizendo, o direito sobre a vida e a morte daqueles 
que se encontram inseridos nesse espaço deslocalizado.

\section{A VIDA NUA E OS NEOMORTOS}

Na obra "O poder soberano e a vida nua - homo sacer" (1998), Agamben afirma que a mesma diz respeito ao secreto ponto de cruzamento entre o modelo jurídicoinstitucional e o modelo biopolítico de poder. Um das conclusões obrigatórias a que chega o autor é precisamente a de que as duas análises não podem ser separadas e que a implicação da vida nua na esfera política constitui o núcleo originário - ainda que oculto - do poder soberano (AGAMBEN, 1998, p.16).

Para o autor a vida nua é "vida exposta à morte e insacrificável do homo sacer" (AGAMBEN 1998, p.17). Baseando-se em Foucault afirma Agambem que "a vida natural começa a ser incluída nos mecanismos e nos cálculos do poder do Estado e a política se transforma em biopolítica", pelo que o homem passa de animal vivo e capaz de existência política para um animal em cuja política sua vida está em jogo (1998, p. 12).

Ainda segundo Foucault, afirma Agambem “a espécie e o indivíduo enquanto simples corpo vivo se tornam uma questão inerente a estratégias políticas" (1998, p. 13), posto que "na biopolítica moderna, soberano é aquele que decide acerca do valor ou não-valor da vida enquanto tal." (1998, p.137), sustentando que

[...] querer dar ao extermínio dos judeus uma aura sacrificial atraés do termo $<<$ holocausto $>>$ é uma irresponsável cegueira historiográfica. O judeu, sob o nazismo, é o referente negativo privilegiado da nova soberania biopolítica e, como tal, um caso flagrante de homo sacer, no sentido de vida exposta à morte $\mathrm{e}$ insacrificável. A sua morte não constitui, portanto, como veremos, nem uma execução capital nem um sacrifício, mas tão-só a actualização de uma mera $<<$ possibilidade de lhe ser infligida a morte $>>$ que é inerente à condição de judeu enquanto tal. A verdade, difícil de aceitar para as próprias vítimas, mas que, no entanto, devemos ter a coragem de não cobrir com véus sacrificiais, é que os judeus não foram exterminados ao longo de um louco e gigantesco holocausto, mas literalmente como Hitler tinha anunciado, $<<$ como piolhos $>>$, isto é, como vida nua. O plano em que se deu o extermínio não é o da religião nem do direito, mas o da biopolítica." (1998, p.111)

Noutra ponta, Agamben destaca que no cenário contemporâneo operou-se uma redefinição da morte com base na ciência médica, a chamada "morte" cerebral que realizou um novo critério de morte, ou seja, o momento em que o paciente deveria ser considerado morto (1998, p.155), neste sentido afirma Agamben que a morte se torna um epifenômeno da tecnologia do transplante, e que a vida e morte, como conceito políticos e não científicos, possuem fronteiras móveis, pois fronteiras biopolíticas (1998, p.157).

Agamben, com base em W. Galyn, refere-se aos chamados neomortos, que seriam aqueles "que teriam o estatuto legal de cadáveres, mas que poderiam manter, tendo em vista eventuais transplantes, algumas características da vida" (1998, p. 157). Em sentido diverso, citando Dagognet, "o corpo que jaz na sala de reanimação" é um falso vivo (faux vivant) "sobre o qual é lícito intervir sem reservas":

Não se surpreende, portanto, que entre os partidários mais convictos da morte cerebral e da biopolítica moderna, se encontre quem invoca a intervenção do Estado na decisão do momento da morte, para que seja consentido intervir sem obstáculos sobre o $<<$ falso vivo $>>$ na sala de reanimação. $<<$ Convém, por isso, 
definir o momento do fim e não aguardar passivamente, como se fazia antes, a rigidez cadavérica e ainda menos os sinais de putrefação, mas ter apenas em conta a morte cerebral [...] Daí decorre a possibilidade de intervir sobre o falso vivo. Só o Estado pode e deve fazê-lo [...] Os organismos pertencem ao poder público: nacionaliza-se o corpo [les organismes appartiennent à la puissance publique: on nationalise le corps: ibid.] $>>$. Nem Reiter nem Verschuer jamais foram tão longe no que diz respeito à politização da via nua; mas (sinal evidente de que a biopolítica ultrapassou um novo liminar) nas democracias modernas é possível dizer publicamente o que os biopolíticos nazis não ousavam dizer. (1988, p.157158 , destaques no original)

Como se vê a intervenção estatal no conceito de morte baseada na ciência médica (politização da vida nua) atinge assim um patamar que muitos não se dão conta.

No Brasil o "estatuto" do paciente em morte cerebral (ser humano vivo e inconsciente, supostamente morto de acordo com o estado da arte da ciência médica) observa única e exclusivamente critérios técnico-médicos:

Lei $\mathrm{n}^{\circ} 9.434 / 97$, Art. $3^{\circ}$ A retirada post mortem de tecidos, órgãos ou partes do corpo humano destinados a transplante ou tratamento deverá ser precedida de diagnóstico de morte encefálica, constatada e registrada por dois médicos não participantes das equipes de remoção e transplante, mediante a utilização de critérios clínicos e tecnológicos definidos por resolução do Conselho Federal de Medicina. (grifos nossos)

Isto é, a Lei de regência sobre a matéria delega a autarquia responsável pela fiscalização do exercício da medicina o estabelecimento dos critérios para o estabelecimento da morte cerebral.

Destaque-se ainda que esse conceito jurídico (legal) de morte cerebral foi o principal fundamento para a procedência da ADPF $\mathrm{n}^{\mathrm{o}} 54$ conforme o voto do relator, Ministro Marco Aurélio:

Enfim, cumpre tomar de empréstimo o conceito jurídico de morte cerebral previsto na Lei $\mathrm{n}^{\circ}$ 9.434/9772, para concluir ser de todo impróprio falar em direito à vida intrauterina ou extrauterina do anencéfalo, o qual é um natimorto cerebral. (grifos nossos)

Esse poder da ciência médica é analisado por Foucault a partir de seus estudos sobre o hospital. Para ele, as transformações sofridas pela instituição hospital, já haviam destacado o aumento do poder médico, vez que "a partir do momento em que o hospital é concebido como um instrumento de cura e a distribuição do espaço torna-se um instrumento terapêutico, o médico passa a ser o principal responsável pela organização hospitalar" (1979, p. 109), além do que passa a ter posição privilegiada, sendo "sua função de higienista, mais que seus prestígios de terapeuta, que lhe assegura esta posição politicamente privilegiada no século XVIII, antes de sê-la econômica e socialmente no século XIX” (1979, p. 203). E continua:

Essa inversão das relações hierárquicas no hospital, a tomada de poder pelo médico, se manifesta no ritual da visita, desfile quase religioso em que o médico, na frente, vai ao leito de cada doente seguido de toda a hierarquia do hospital: assistentes, alunos, enfermeiras, etc. Essa codificação ritual da visita, que marca o advento do poder médico, é encontrada nos regulamentos de hospitais do século XVIII, em que se diz onde cada pessoa deve estar colocada, que o médico deve ser anunciado por uma sineta, que a enfermeira deve estar na porta com um caderno nas mãos e deve acompanhar o médico quando ele entrar, etc. (1979, p. 
110)

A medicina passa a ser, então, de grande interesse para o Estado, que se utilizando dos mecanismos jurídicos passa a disciplinar e controlar a saúde, recebendo a medicina sanitarista suporte jurídico, inclusive com criação de Códigos Sanitários e até mesmo uma polícia sanitária (STANCIOLI, 2004. p. 17).

A medicina como técnica geral de saúde, mais do que como serviço das doenças e arte das curas, assume um lugar cada vez mais importante nas estruturas administrativas e nesta maquinaria de poder que, durante o século XVIII, não cessa de se estender e de se afirmar. O médico penetra em diferentes instâncias de poder. A administração serve de ponto de apoio e, por vezes, de ponto de partida aos grandes inquéritos médicos sobre a saúde das populações; por outro lado, os médicos consagram uma parte cada vez maior de suas atividades a tarefas tanto gerais quanto administrativas que lhes foram fixadas pelo poder. Acerca da sociedade, de sua saúde e suas doenças, de sua condição de vida, de sua habitação e de seus hábitos, começa a se formar um saber médico-administrativo que serviu de núcleo originário à "economia social" e â sociologia do século XIX. (FOUCAULT, 1979, p. 202)

Naquele momento histórico não muito distante (início do século $\mathrm{XX}$ ) a "dogmática jurídica cuidava de legitimar a total aniquilação da vontade, autonomia e privacidade dos enfermos" (STANCIOLI, 2004. p. 19), vez que eram conduzidos os doentes para hospitais de isolamento sem qualquer compreensão ou justificativa do que lhes ocorria. Eram conduzidos para o seu leito de morte, posto que os hospitais eram o local onde se morria, como menciona Foucault:

O hospital como instrumento terapêutico é uma invenção relativamente nova, que data do final do século XVIII. A consciência de que o hospital pode e deve ser um instrumento destinado a curar aparece claramente em torno de 1780 e é assinalada por uma nova prática: a visita e a observação sistemática e comparada dos hospitais. (1979, p. 99)

Neste particular Foucault recebe a crítica de Agamben para quem "a investigação que se tinha iniciado com a reconstrução do grand enferment nos hospitais e nas prisões, não se conclui com uma análise do campo de concentração" (1998, p. $115)$.

A crítica de Agamben é compreensível, pois é nos campos de concentração, e em particular nos campos de extermínio, que o ápice da biopolítica (ou melhor, da tanatopolítica) se dá:

Em Auschwitz não se morria: produziam-se cadáveres. Cadáveres sem morte, não-homens cujo falecimento foi rebaixado a produção em série. É precisamente a degradação da morte que constituiria, segundo uma possível e difundida interpretação, a ofensa específica de Auschwitz, o nome próprio do seu horror. (AGAMBEN, 2008, p. 78)

Para Agamben a fusão entre a medicina e a política é uma das características essenciais da biopolítica moderna, para quem o médico e o soberano parecem trocar de papéis (1998, p.137).

Agamben cita o caso dos médicos Schumann e Baumhardt que eram os responsáveis por um programa de eutanásia situado na cidade de Grafeneck, os quais "submetiam os doentes a uma visita sumária e decidiam se eles satisfaziam os requisitos exigidos pelo programa. Na maior parte dos casos, os doentes eram mortos nas 24 horas a seguir a chegada a Grafeneck" (1998, p. 135), tudo isso sob a bandeira de "eliminação 
da vida indigna de ser vivida" (1998, p.134).

Indiscutivelmente, a situação das pessoas que eram utilizadas como cobaias humanas pelo regime nazista demonstra o rompimento de qualquer limite éticocientífico, pois "[...] as experiências realizadas por médicos e investigadores alemães nos campos de concentração foram universalmente consideradas como um dos capítulos mais infames a história do regime nacional-socialista." (1998, p. 148), sendo certo que "no horizonte biopolítico que caracteriza a modernidade, o médico e o cientista se movem na terra de ninguém em que, outrora, só o soberano podia penetrar" (1998, p.152).

Desta feita, não se pode perder de vista esse paradigma contemporâneo, tendo-se em mente que o campo e o estado de exceção estão sempre virtualmente presentes e que o conhecimento científico pode, a qualquer tempo, ser utilizado pelo poder estatal, com os riscos inerentes às conveniências do governo.

Por fim, é de se referir que Mbembe também critica Foucault ao afirmar que a noção de biopoder não é capaz de "dar conta das formas contemporâneas de submissão da vida ao poder da morte", propondo a noção de necropolítica e necropoder (2018, p.71), partindo do pressuposto de que "[...] a expressão máxima da soberania reside, em grande medida, no poder e na capacidade de ditar quem pode viver e quem deve morrer", tendo em vista que "ser soberano é exercer controle sobre a mortalidade e definir a vida como implantação e manifestação do poder." (MBEMBE, 2018, p. 5), na medida em que "a soberania é a capacidade de definir quem importa e quem não importa, quem é 'descartável' e quem não é.” (MBEMBE, 2018, p. 41)

$\mathrm{O}$ anteriormente mencionado rompimento de limite ético-científico persiste na atualidade, pois, conforme Mbembe, quando o valor e utilidade das pessoas "não são demonstrados, podem ser destruídas como escravos, peões ou clientes.” (MBEMBE, 2018, p. 56)

\section{CONSIDERAÇÕES FINAIS}

O conceito clássico de Estado-nação não sustenta na contemporaneidade, tendo em vista que os elementos tidos por essenciais passam a não mais se mostrarem presentes em certas conjunturas.

Configura-se o campo como um novo elemento essencial do conceito de Estadonação, compreendendo-se o estado de exceção não como a clássica suspensão normativa temporária, mas sim como uma localização deslocante contida no espaço territorial, a qual deve ser entendida como técnica de governo.

Contemporaneamente, mesmo nos estados chamados democráticos, encontra-se, ainda que não seja declarado oficialmente, o "estado de exceção", havendo, pois a presença do campo.

$\mathrm{O}$ estado de exceção tem estreita relação com a necessidade, sendo a sua natureza subjetiva e não objetiva, logo não há supostamente neutralidade, mas sim juízos subjetivos, pois que a decisão sobre o estado de exceção com base na necessidade é uma decisão sobre a própria necessidade.

Como exemplos de uso indiscriminado do poder do soberano refere-se o uso abusivo das medidas provisórias, o qual daria conta dessa realidade no Estado-nação contemporâneo brasileiro.

$\mathrm{O}$ direito sobre a vida e a morte daqueles que se encontram inseridos nesse espaço deslocalizado chamado estado de exceção é questão central da biopolítica.

A ciência médica redefiniu o conceito de morte através de um novo critério, 
qualificando-a, ou seja, agora existe a possibilidade de um ser vivo passar a ser considerado morto. Trata-se do conceito de morte cerebral.

Nesse sentido, a vida e a morte "possuem fronteiras móveis", posto que estas fronteiras são biopolíticas, sendo a intervenção estatal no conceito de morte baseada na ciência médica (politização da vida nua).

Como exemplo referiu-se que no Brasil, o Art. $3^{\circ}$ da Lei $n^{\circ} 9.434 / 97$, observa única e exclusivamente critérios técnico-médicos estabelecidos pelo Conselho Federal de Medicina (CFM) conforme a determinação legal. Ou seja, a Lei de regência sobre a matéria delega a autarquia responsável pela fiscalização do exercício da medicina o estabelecimento dos critérios para o estabelecimento da morte cerebral.

Destacou-se ainda que esse conceito jurídico (legal) de morte cerebral foi o principal fundamento do ministro relator no STF para a procedência da $\operatorname{ADPF} n^{\circ} 54,0$ qual considerou o feto anencéfalo um "natimorto cerebral".

Referiu-se que Foucault analisou as transformações sofridas pela instituição hospitalar, destacando o aumento do poder médico, sendo certo que a medicina passou a ser de grande interesse para o Estado, que se utilizando dos mecanismos jurídicos passa a disciplinar e controlar a saúde, e via de consequência, vida e morte com base na ciência.

Agamben critica Foucault porque ele não teria avançado em seus estudos dos hospitais e das prisões para o campo de concentração, posto que foi nos campos de concentração, e em particular nos campos de extermínio, que o ápice da biopolítica (tanatopolítica) se deu, tendo em vista que em Auschwitz as pessoas não eram mortas, "produziam-se cadáveres".

Para Agamben a fusão entre a medicina e política é uma das características essenciais da biopolítica moderna, onde "médico e o soberano parecem trocar de papéis", decidindo tanto quanto outrora decidia o soberano.

Desta feita, não pode perder de vista esse paradigma contemporâneo, tendo-se em mente que o campo e o estado de exceção estão sempre virtualmente presentes e que o conhecimento científico pode, a qualquer tempo, ser utilizado pelo poder estatal, com os riscos inerentes às conveniências do governo.

\section{REFERÊNCIAS}

AGAMBEN, Giorgio. O poder soberano e a vida nua - homo sacer. Lisboa: Editorial Presença, 1998.

AGAMBEN, Giorgio. Estado de Exceção. São Paulo: Boitempo, 2004.

AGAMBEN, Giorgio. O que resta de Auschwitz: o arquivo e a testemunha (Homo sacer III). São Paulo: Boitempo, 2008.

AGAMBEN, Giorgio. Meios sem fim: notas sobre a política. Belo Horizonte: Autêntica Editora, 2015.

BRESSER-PEREIRA, Luiz Carlos. NAÇÃO, ESTADO E ESTADO-NAÇÃO. Disponível em http://www.bresserpereira.org.br/papers/2008/08.21.Na\%C3\%A7\%C3\%A3o.Estado.Esta do-Na\%C3\%A7\%C3\%A3o-Mar\%C3\%A7o18.pdf. Acesso em: 01 de março de 2017.

CASTRO, Edgardo. Introdução a Giogio Agamben: uma arqueologia da potência. Belo Horizonte: Autêntica, 2012.

CAVALCANTI, Francisco Ivo Dantas. Teoria do estado: direito constitucional I. Belo Horizonte: Livraria Del Rey, 1989.

DALLARI, Dalmo de Abreu. Elementos de teoria geral do estado. São Paulo: Saraiva, 2007.

FAYET JUNIOR, Ney; SOUZA, Draiton Gonzaga de. Da insubmersibilidade dos desafios éticos da ciência moderna em face do Estado Constitucional Democrático: a (questão da) Kastration de condenados por delitos sexuais graves. in Interesse Público - IP, Belo 
Horizonte, ano 17, n. 92, p. 37-58, jul./ago. 2015.

FOUCAULT, Michel. Microfisica do Poder. Rio de Janeiro: Graal, 1979.

MATOS, Saulo M. M. de. Teoria pura do direito e nazismo: uma análise a partir da crítica de Gustav Radbruch. In Direitos humanos e crítica teórica. COSTA, Paulo Sérgio Weyl A.; CULLETON, Alfredo; COLARES Virgínia (Organizadores). Porto Alegre: Entrementes, 2015.

MBEMBE, Achille. Necropolitica: biopoder, estado de exceção, política da morte. São Paulo: n1 edições, 2018.

ROMAGUERA, Daniel Carneiro Leão; TEIXEIRA, João Paulo Allain; BRAGATO, Fernanda Frizzo. Por uma crítica descolonial da ideologia humanista dos direitos humanos. In Derecho y Cambio Social. Disponível em:

https://dialnet.unirioja.es/descarga/articulo/5470223.pdf. Acesso em: 01 de março de 2017.

ROMAGUERA, Daniel Carneiro Leão; TEIXEIRA, João Paulo Allain. Para além do poder soberano: uma crítica à herança moderna e legitimação. In Direitos humanos e crítica teórica. COSTA, Paulo Sérgio Weyl A.; CULLETON, Alfredo; COLARES Virgínia (Organizadores). Porto Alegre: Entrementes, 2015.

STAMFORD DA SILVA, Artur. 10 lições sobre Luhmann. Petrópolis: Vozes, 2016.

STANCIOLI. Brunello Souza. Relação jurídica médico-paciente. Belo Horizonte: Del Rey, 2004.

STRECK, Lênio Luiz; MORAIS, José Luis Bolzan. Ciência politica e teoria geral do estado. Porto Alegre: Livraria do Advogado Editora, 2004.

SCZIMINSKI, Terezinha de Fátima Juraczky; BAZZANELLA, Sandro Luiz. A SOBERANIA E A EXCEÇÃO NO PENSAMENTO DE GIORGIO AGAMBEN E CARL SCHMITT. In Revista Estação Científica. Juiz de Fora, nº 09, janeiro - junho / 2013.

STF - Supremo Tribunal Federal. ADPF $n^{\circ} 54$. Voto Ministro Marco Aurélio Melo. Disponível em: http://www.stf.jus.br/arquivo/cms/noticianoticiastf/anexo/adpf54.pdf. Acesso em 01 de março de 2017. 